\title{
Lack of familial predisposition to cardiovascular disease in Type 1 (insulin-dependent) diabetic patients with nephropathy
}

\author{
K.Nørgaard, E. R.Mathiesen, E.Hommel, J.S.Jensen and H.-H.Parving \\ Steno Memorial and Hvidøre Hospital, Copenhagen, Denmark
}

Summary. A familial predisposition has been proposed as a major determinant of the increased morbidity and mortality from cardiovascular disease demonstrated in Type 1 (insulindependent) diabetic patients with nephropathy. We assessed this concept by studying 91 parents of Type 1 diabetic patients with nephropathy and 94 parents of aged-matched Type 1 diabetic patients with normoalbuminuria. The two groups of parents were of a similar age $(58 \pm 8$ vs $58 \pm$ 7 years). The prevalence (\%) of death and cardiovascular diseases (World Health Organisation questionnaire) was 10 (4-18)\% and $12(6-21) \%$ in parents of nephropathic patients compared to $8(3-16) \%$ and $13(6-23) \%$ in parents of normoalbuminuric Type 1 diabetic patients. The frequency of risk factors for cardiovascular disease were about the same in both groups of parents. Microalbuminuria was found in 5\% and $11 \%$, hypercholesterolaemia $(>6.5 \mathrm{mmol} / \mathrm{l})$ in $25 \%$ and $26 \%$ and smokers constituted $40 \%$ and $34 \%$ of parents of patients with and without proteinuria, respectively. A familial predisposition to cardiovascular disease cannot explain the increased morbidity and mortality from cardiovascular disease in young patients with diabetic nephropathy.

Key words: Type 1 (insulin-dependent) diabetes mellitus, diabetic nephropathy, cardiovascular disease, familial predisposition.
Diabetic nephropathy develops in $30-40 \%$ of all Type 1 (insulin-dependent) diabetic patients. End stage renal failure is the leading cause of death followed by cardiovascular diseases (CVD) [1]. The relative mortality of CVD is on average increased 40-fold in diabetic nephropathy. In young diabetic patients with nephropathy (age 25 to 35 years) the relative mortality of CVD is highest (increased by as much as 186-fold) [1]. The presence of the well-known cardiovascular risk factors cannot alone account for this fact [2]. Recently, it was proposed that a familial predisposition to CVD was present in Type 1 diabetic patients with nephropathy [3]. The purpose of our present study was to evaluate if a familial predisposition to cardiovascular disease could in part explain the increased mortality and morbidity from CVD in Type 1 diabetic patients with diabetic nephropathy.

\section{Subjects and methods}

\section{Subjects}

At the Steno Memorial and Hvidøre Hospital we identified all Type 1 diabetic patients below the age of 33 years with clinical diabetic nephropathy i.e. urinary albumin excretion (UAE) above
$300 \mathrm{mg} / 24 \mathrm{~h}$ in at least two of the last three consecutive, sterile urine specimens. Diabetes onset was prior to age 20 years. Patients with non-diabetic kidney or renal tract diseases were excluded. A group of normoalbuminuric (UAE $<20 \mathrm{mg} / 24 \mathrm{~h}$ ) Type 1 diabetic patients matched for age, sex and diabetes duration was also consecutively selected. Only patients with at least one parent living in a geographically well-defined area (Greater Copenhagen and surroundings) were included. None of the diabetic patients identified had lost both parents. Fifty-eight patients with nephropathy and 54 with normoalbuminuria fulfilled this criteria. Of the eligible 224 parents 185 (91 parents of patients with nephropathy and 94 parents of normoalbuminuric patients) participated ( $83 \%$ ) in the study. The 39 parents not studied did not differ from those investigated with respect to age and sex. The present study is a 2 -year follow-up of a previous published study with a complete description of the material [4].

\section{Design}

All the parents were invited to our clinic for an health-interview and blood sampling. The interview was based on the Rose questionnaire on cardiovascular disease [5]. Furthermore, their smoking habits and medicine intake were recorded. Cardiovascular disease was diagnosed if anamnestic evidence of angina pectoris, myocardial infarction, intermittent claudication and/or cerebral ischaemia was given. Parents with diabetes were excluded from further evaluation. The causes of death of the dead parents were obtained from their off- 
patic patients $(102 \pm 52$ vs $74 \pm 13 \mu \mathrm{mol} / 1$, and 928 (5001781) vs 10 (6-14) $\mathrm{mg} / 24 \mathrm{~h}$, respectively) [4].

Data concerning the parents are given in Table 1. Diabetes was seen in seven parents to $\mathrm{DN}+$ and in ten parents of DN -, (NS). The prevalence of death and CVD were nearly identical in the two groups of parents $(10 \%$ vs $8 \%$ and $12 \%$ vs $13 \%$, respectively). No significant differences were found between the groups according to the causes of death (Table 2). Out of 76 parents of DN + and 77 parents of $\mathrm{DN}$ - angina pectoris was seen in three and five, myocardial infarction in one and two, intermittent claudication in one and two, and cerebral ischaemia in four and one, respectively.

A daily record was kept of drug intake in $34 \%$ of the parents of $\mathrm{DN}+$ and in $40 \%$ of the parents of $\mathrm{DN}-$. This was accounted for mainly by hormone intake by postmenopausal females. Daily use of antihypertensive, cardiac stimulating drugs or nitroglycerine was seen in $13 \%$ and $10 \%$, respectively.

Serum cholesterol was similar in both groups. A serum cholesterol above $6.5 \mathrm{mmol} / \mathrm{l}$ was observed in $25 \%$ of the $\mathrm{DN}+$ parents and $26 \%$ of the $\mathrm{DN}-$ parents. Timed overnight UAE was equal in the two groups of parents and the prevalence of microalbuminuria was $5 \%$ in parents of $\mathrm{DN}+$ and $11 \%$ in parents of DN - (NS). At the time of the study $41 \%$ and $34 \%$, respectively, (NS) of the parents smoked tobacco.

\section{Discussion}

The morbidity and mortality of cardiovascular diseases were practically identical in the parents of young Type 1 diabetic patients with diabetic nephropathy and parents of diabetic patients with normoalbuminuria. Furthermore, the prevalence of cardiovascular risk factors, such as hypercholesterolaemia, microalbuminuria and smoking were nearly the same in the two groups of parents.

The epidemiological method applied for detection of cardiovascular diseases has a high specificity and reasonable sensitivity [5]. Originally, Rose found that the sensitivity and specificity for angina pectoris was $81 \%$ and $91 \%$, for myocardial infarction $87 \%$ and $91 \%$ and for intermittent claudication $92 \%$ and $100 \%$, respectively. The age of the subjects in the present study was nearly identical to the age of the patients studied by Dr. Rose, while the number of subjects we studied exceeded the number investigated in that study [5].

The ascertainment of the living parents is high (83\%) and we have obtained information regarding the causes of death in all non-survivors.

The prevalence of CVD in parents of diabetic patients was comparable to the prevalence of CVD in the Danish background population of similar age (The Glostup Population) [7]. The prevalence of CVD increases with age in the general population [7]. Thus, it is of no surprise that Earle et al. [3] found a higher prevalence of CVD as compared with the present study, where the parents are 8 years younger. They found, however, a significantly higher prevalence of CVD in parents of albuminuric Type 1 diabetic patients (46\%) than in parents of nor-
Table 1. Clinical data, prevalence of death, cardiovascular risk factors, and cardiovascular disease (CVD) in parents of Type 1 (insulindependent) diabetic patients with nephropathy and in parents of Type 1 diabetic patients with normoalbuminuria

\begin{tabular}{|c|c|c|}
\hline & \multicolumn{2}{|c|}{ Parents of diabetic patients } \\
\hline & $\begin{array}{l}\text { With } \\
\text { nephropathy }\end{array}$ & $\begin{array}{l}\text { With normo- } \\
\text { albuminuria }\end{array}$ \\
\hline Sex (female/male) & $35 / 41$ & $32 / 45$ \\
\hline Age (years) & $58 \pm 8(43-79)$ & $58 \pm 7(43-71)$ \\
\hline Prevalence of death $(\%)$ & $10(4-18)$ & $8(3-16)$ \\
\hline Prevalence of CVD (\%) & $12(6-21)$ & $13 \quad(6-23)$ \\
\hline $\begin{array}{l}\text { Urinary albumin excretion } \\
(\mu \mathrm{g} / \mathrm{min})\end{array}$ & $4 \quad(1-214)$ & $5 \quad(1-68)$ \\
\hline $\begin{array}{l}\text { Prevalence of microalbumin- } \\
\text { uria }(\%)\end{array}$ & $5 \quad(1-14)$ & $11 \quad(4-21)$ \\
\hline Serum cholesterol $(\mathrm{mmol} / \mathrm{l})$ & $5.7 \pm 1.2$ & $5.8 \pm 1.0$ \\
\hline Percentage of smokers & $40(29-52)$ & $34(24-46)$ \\
\hline
\end{tabular}

mean $\pm \mathrm{SD}$, median (range), prevalence $(95 \% \mathrm{Cl})$

Table 2. The causes of death in parents of Type 1 (insulin-dependent) diabetic patients with and without nephropathy

\begin{tabular}{lll}
\hline & \multicolumn{2}{l}{ Parents of diabetic patients } \\
\cline { 2 - 3 } & $\begin{array}{l}\text { With } \\
\text { nephropathy }\end{array}$ & $\begin{array}{l}\text { With normo- } \\
\text { albuminuria }\end{array}$ \\
\hline Carcinoma & 4 & 2 \\
Myocardial infarction & 1 & 2 \\
Diabetic nephropathy & 1 & 2 \\
Chronic obstructive lung disease & 1 & 0 \\
Suicide & 1 & 0 \\
Alcoholic liver disease & 0 & 1 \\
\hline
\end{tabular}

spring, general practitioner, hospital records, death certificates and autopsy reports. The participants were carefully instructed to collect two timed overnight urine samples. The samples were analysed for albumin excretion by an ELISA-method [6]. Microalbuminuria was defined as UAE above $14 \mu \mathrm{g} / \mathrm{min}$ in both urine samples. Serum cholesterol was determined enzymatically by the cholesterol oxidase/peroxidase aminophenazone method (interassay variation $2.1 \%$ ), (Boehringer, Mannheim, FRG).

\section{Statistical analysis}

Data are expressed as mean \pm SD except for UAE which is given as median and range. Prevalences are given by actual values and $95 \%$ confidence intervals. Comparisons between the groups were done by the Student's unpaired $t$-test and for the UAE the non-parametric Mann-Whitney test was used. The prevalences were compared using Chi-squared test. A $p$-value less than 0.05 was considered significant.

\section{Results}

The two groups of diabetic patients (Type 1 diabetic patients with nephropathy $(\mathrm{DN}+)$ and with normoalbuminuria (DN - ), respectively) were comparable regarding age ( $29 \pm 3$ vs $30 \pm 3$ years), sex-distribution and diabetes duration ( $20 \pm 4$ vs $19 \pm 4$ years). Serum creatinine and UAE was significantly elevated in the nephro- 
moalbuminuric Type 1 diabetic patients (23\%). There is no obvious explanation for the discrepancy between the two studies in relation to prevalence of death and cardiovascular risk factors between parents of Type 1 diabetic patients with and without nephropathy.

If present, any difference between predisposition to CVD among DN + and DN - would at least have been detected as a different prevalence of the risk factors to these diseases. In non-diabetic subjects it has been found that microalbuminuria is a predictor of cardiovascular mortality $[8,9]$. We found no difference in the prevalence of microalbuminuria among the two groups of parents as we found no difference in the prevalence of hypercholesterolaemia, smoking habits and medicine intake. Furthermore, we have previously reported a similar prevalence of hypertension and a similar blood pressure in these two groups of parents [4].

From our data we conclude that a familial predisposition to cardiovascular disease cannot explain the increased morbidity and mortality from cardiovascular disease in young Type 1 diabetic patients with nephropathy.

\section{References}

1. Borch-Johnsen K, Kreiner S (1987) Proteinuria - a predictor of cardiovascular mortality in insulin-dependent diabetes mellitus. Br Med J 294: 1651-1655

2. Jensen T, Stender S, Deckert T (1988) Abnormalities in plasma concentrations of lipoproteins and fibrinogen in Type 1 (insulin- dependent) diabetic patients with increased urinary albumin excretion. Diabetologia 31: 142-145

3. Earle KA, Walker JD, Jones SL, Hill C, Viberti GC (1990) Cardiovascular disease in the parents of Type 1 (insulin-dependent) diabetics with nephropathy. Diabetologia 33: 219 (Abstract)

4. Jensen JS, Mathiesen E, Nørgaard K et al. (1990) Increased blood pressure and erythrocyte sodium/lithium countertransport activity are not inherited in diabetic nephropathy. Diabetologia 33: 619-624

5. Rose GA (1962) The diagnosis of ischaemic heart pain and intermittent claudication in field surveys. Bull Wld Hlth Org 27: 645658

6. Feldt-Rasmussen B, Dinesen B, Deckert M (1985) Enzyme immuno assay - an improved determination of urinary albumin in diabetics with incipient nephropathy. Scand J Clin Lab Invest 45 : 539-544

7. Agner E, Damm P, Hansen PF, Schroll M (1982) Causes of hospitalisation in different age intervals. Dan Med Bull 29: 140-144

8. Damsgaard EM, Frøland A, Jørgensen OD, Morgensen CE (1990) Microalbuminuria as predictor of increased mortality in elderly people. Br Med J 300: 297-300

9. Yudkin JS, Forrest RD, Jackson CA (1988) Microalbuminuria as predictor of vascular disease in non-diabetic subjects: Islington Diabetes Survey. Lancet II: 530-533

Received: 7 January 1991

and in revised form: 19 March 1991

Dr. K. Nørgaard

Steno Memorial and Hvidøre Hospital

2 Niels Steensensvéj

DK-2820 Gentofte

Denmark

\section{Erratum}

\section{Diabetologia, Volume 33, Number 8, August 1990, pp. 449-456}

S. Tissot et al: Use of new gas chromatograph isotope ratio mass spectrometer to trace exogenous ${ }^{13} \mathrm{C}$ labelled glucose at a very low level of enrichment in man
On page 451 in the formula for transformation of measured $\delta^{13} \mathrm{C} \%$ in ${ }^{13} \mathrm{C}$ atom \% (AP),

$\mathrm{AP}=\operatorname{atom} \%=\frac{100 \mathrm{R} \times\left(0.001 \delta^{13} \mathrm{C}_{S}+1\right)}{1+\left(\mathrm{R} \times 0.001 \delta^{13} \mathrm{C}_{S}+1\right)}$

should read:

$\mathrm{AP}=$ atom $\%=\frac{100 \mathrm{R} \times\left(0.001 \delta^{13} \mathrm{C}_{S}+1\right)}{1+\mathrm{R}\left(0.001 \delta^{13} \mathrm{C}_{\mathrm{S}}+1\right)}$ 